\title{
miR-301a promotes lung tumorigenesis by suppressing Runx3
}

\author{
Xun $\mathrm{Li}^{1 \dagger}$, Mingtian Zhong ${ }^{2 \dagger}$, Jiexuan Wang ${ }^{3 \dagger}$, Lei Wang ${ }^{1}$, Zhanwen Lin ${ }^{1}$, Zhi Cao ${ }^{2}$, Zhujuan Huang ${ }^{2}$, \\ Fengxue Zhang ${ }^{2}$, Yong $\mathrm{Li}^{4}$, Ming $\mathrm{Liu}^{3 *}$ and Xiaodong $\mathrm{Ma}^{1,2^{*}}$ (D)
}

\begin{abstract}
Background: Our previous report demonstrated that genetic ablation of miR-301a reduces Kras-driven lung tumorigenesis in mice. However, the impact of miR-301a on host anti-tumor immunity remains unexplored. Here we assessed the underlying molecular mechanisms of miR-301a in the tumor microenvironment.

Methods: The differentially expressed genes were identified by using deep sequencing. The immune cell counts, and cytokines expression were analyzed by realtime PCR, immunohistochemistry and flow cytometry. The role of miR-301a/Runx3 in lung tumor was evaluated on cell growth, migration and invasion. The function of miR-301a/ Runx3 in regulating tumor microenvironment and tumor metastasis were evaluated in Kras transgenic mice and B16/LLC1 syngeneic xenografts tumor models.

Results: In this work, we identified 1166 up-regulated and 475 down-regulated differentially expressed genes in lung tumor tissues between $\mathrm{Kras}^{L A 2}$ and $\mathrm{miR}_{-301 a^{-1-}} ; \mathrm{Kras}^{L A 2}$ mice. Immune response and cell cycle were major pathways involved in the protective role of miR-301a deletion in lung tumorigenesis. Overexpression of the miR301a target, Runx3, was an early event identified in miR-301a ${ }^{-1-}$; $\mathrm{Kras}^{\mathrm{LA2}}$ mice compared to WT-Kras ${ }^{\text {LA2 }}$ mice. We found that miR-301a deletion enhanced $\mathrm{CD}^{+} \mathrm{T}$ cell accumulation and IFN- $\gamma$ production in the tumor microenvironment and mediated antitumor immunity. Further studies revealed that miR-301a deficiency in the tumor microenvironment effectively reduced tumor metastasis by elevating Runx3 and recruiting CD $8^{+} \mathrm{T}$ cells, whereas miR-301a knockdown in tumor cells themselves restrained cell migration by elevating Runx3 expression.
\end{abstract}

Conclusions: Our findings further underscore that miR-301a facilitates tumor microenvironment antitumor immunity by Runx3 suppression in lung tumorigenesis.

Keywords: miR-301a, Kras, CD8 ${ }^{+}$T cells, Runx3, IFN- $\gamma$

\section{Background}

Lung adenocarcinoma is the most common NSCLC and develops in the pulmonary mucus-producing cells. Generally, lung adenocarcinoma manifests initially as adenoma hyperplasia, which progresses to bronchio-alveolar carcinoma and finally to invasive adenocarcinoma [1]. Activation of oncogenic Kras induces lung adenocarcinoma and its evolution through a series of morphological

\footnotetext{
* Correspondence: 34121647@qq.com; sciencema@hotmail.com

${ }^{+}$Xun Li, Mingtian Zhong and Jiexuan Wang contributed equally to this work.

${ }^{3}$ State Key Laboratory of Respiratory Disease, Guangzhou Institute of Respiratory Health, The First Affiliated Hospital of Guangzhou Medical University, Guangzhou Medical University, Guangzhou 510120, China ${ }^{1}$ Institute for Brain Research and Rehabilitation, Guangdong Key Laboratory of Mental Health and Cognitive Science, Center for Studies of Psychological Application, South China Normal University, Guangzhou 510631, China Full list of author information is available at the end of the article
}

stages from mild hyperplasia to overt carcinoma. With inactivation of tumor suppressor genes, such as Trp53 or Pten, Kras significantly accelerates NSCLC malignancy $[2,3]$. In primary cells such as mouse embryonic fibroblast (MEFs), Kras activation alone induced cellular senescence; however, it caused cellular transformation when $\operatorname{Tr} 553$ mutation was also present [4]. Either suppression of Kras signaling or restoration of Trp53 function is sufficient to cause regression of lung tumors in mice, supporting the possibility that Kras and Trp53 are therapeutic targets in NSCLC [5]. Interestingly, in mouse models with Trp53 mutation, restoration of wild-type (WT) Trp53 inhibits growth of lung adenocarcinoma, but has no effects on adenoma formation [6, 7]. These data suggest that mutation of tumor suppressor

(C) The Author(s). 2019 Open Access This article is distributed under the terms of the Creative Commons Attribution 4.0 International License (http://creativecommons.org/licenses/by/4.0/), which permits unrestricted use, distribution, and 
genes contributes to the early stages of cell transformation and lung tumorigenesis.

Of more than 1000 microRNAs identified, miR-301a has been reported to be overexpressed in several tumor types, including lung [8-10], colon [11], and pancreatic cancer [12]. Mounting evidence indicates that miR-301a is a potential oncogenic miRNA and contributes to tumor formation [11, 13]. Inhibition of miR-301a reduces anchorage-independent colony formation of lung cancer cells [13]. In the orthotopic model of Lewis lung cancer, overexpression of miR-301a in dendritic cells decreased IFN- $\gamma$ release from antigen-specific cytotoxic $\mathrm{T}$ cells, which shifted the antigen-specific $\mathrm{T}$ helper cytokine profile from IFN- $\gamma$ toward IL-13 and IL-17A [14]. Our previous studies showed that deletion of miR-301a reduces Kras-driven lung tumorigenesis in mice, suggesting that miR-301a overexpression promotes lung tumorigenesis [15]. In $\mathrm{Kras}^{L A 2}$ mice, miR-301a expression in lung or spleen was highest at 9 weeks of age and started to decline at 13 and 18 weeks. Interestingly, miR-301a expression in spleens was upregulated 9.4-fold, whereas that in lung tumors was upregulated only 2.6-fold. Furthermore, deletion of miR-301a in hematopoietic cells leads to reduced development of colitis-associated colon cancer [15]. In patients with NSCLC, miR-301a is most highly expressed in tumor tissues and is associated with poor differentiation and lymph node metastasis [16]. Collectively, these in vitro and in vivo data indicate that miR-301a has an important role in the tumor microenvironment and tumor metastasis.

Runt-related transcription factor 3 (RUNX3) was validated to be a direct target of miR-301a and downregulating of RUNX3 by miR-301a was demonstrated to promote gastric and colorectal cancer cell proliferation and metastasis is. [11, 17]. As a downstream effector of the transforming growth factor- $\beta$ (TGF- $\beta$ ), RUNX3 play a critical role in regulation of tumor cell migration, invasion, and epithelial-to-mesenchymal transition (EMT) [18]. RUNX3 forms a ternary complex with $\beta$-catenin/ TCF to inhibit Wnt signaling activity in glioma, gastric and intestinal cancers [19-21]. Overexpression of RUNX3 was demonstrated to inhibit EMT, which promotes metastasis and loss of RUNX3 in epithelial cells are sensitized to TGF $\beta$ induced EMT [21, 22]. Excessive EMT was observed in lung tissue in Runx3 deficient mice and pharmacologic inhibition of EMT expands life spans of new born mice, which was partially due to downregulation of EMT [23]. In Kras-induced lung tumorigenesis, RUNX3 can activate the $\mathrm{p} 14^{\mathrm{ARF}}-\mathrm{p} 53$ pathway to inhibit the lung adenoma formation [24].

To determine the exact mechanisms of how miR-301a engages Kras-driven lung tumorigenesis, we used RNA deep sequencing to further analyze the molecular mechanisms involved in the role of miR-301a in lung tumorigenesis. We found that the immune response and cell cycle were the major pathways that differed between $\mathrm{Kras}^{L A 2}$ and $\mathrm{miR}-301 a^{-1-}$;Kras ${ }^{L A 2}$ mice. Notably, we revealed that deletion of miR-301a leads to $\mathrm{CD}^{+} \mathrm{T}$ cell accumulation, IFN- $\gamma$ production, and tumor metastatic suppression by elevating Runx3, suggesting that miR-301a is a key regulator of the tumor microenvironment in the initiation of tumorigenesis.

\section{Methods \\ Mice and cell lines}

Generation of $m i R-301 a^{-/-}$mice in the C57BL/6X129S hybrid background has been described previously [15]. $\mathrm{Kras}^{L A 2}$ mice were purchased from the Jackson Laboratory and bred with $m i R-301 a^{-/-}$mice to obtain $m i R-301$ $a^{-/} ; K_{r a s}{ }^{L A 2}$ mice. Human noncancerous bronchial cell line 16HBE and adenocarcinoma cell lines A549, NCI-H1975 (H1975) and NCI-H1299 (H1299) were purchased and authenticated from the ATCC. PC-9 cell line was purchased and authenticated from the Cell Bank of Type Culture Collection of Chinese Academy of Sciences. Splenocytes, $\mathrm{CD}^{+} \mathrm{T}$ cells, $\mathrm{CD} 8^{+} \mathrm{T}$ cells, $\mathrm{CD} 11 \mathrm{~b}^{+}$cells, and $\mathrm{CD} 11 \mathrm{c}^{+}$cells were isolated from spleens or tumors using MACS MicroBeads (Miltenyi Biotec, San Diego, CA, USA) following the manufacturer's instruction.

\section{Tumor metastasis models}

WT and $m i R-301 a^{-/-}$mice $(20-23 \mathrm{~g}$, age $8-10$ weeks) were used for B16 or LLC1 tumor metastasis models following an established protocol $[25,26] .2 .5 \times 10^{5}$ B16 or LLC1 cells were injected into WT and miR-301a $a^{-1-}$ mice via the tail vein, and after $24 \mathrm{~h}, 200 \mu \mathrm{l}$ lentivirus supernatant with either shRNA-control or shRNA-Runx3 was injected into the tail vein every other day until tissue collection. At 4 weeks post-injection, mice were euthanized by $\mathrm{CO}_{2}$ asphyxiation. Lung tissues were removed and fixed with $4 \%$ formaldehyde, and lung metastasis sites were evaluated by histological observation.

\section{RNA preparation and sequencing}

Total RNA was extracted using the TRI Reagent and Direct-zol RNA kit (Zymo Research, Irvine, CA, USA) following the manufacturer's instructions. RNA quality and quantity were assessed on an Agilent Bioanalyzer 2100 to ensure an A260/A280 ratio in the range of 1.8-2.0 and an RNA ratio $(28 \mathrm{~S} / 18 \mathrm{~S})>1.0$. DNA was removed with DNase I. Poly(A) RNAs were purified by using the Dynabeads mRNA purification kit (Invitrogen, Carlsbad, CA, USA) according to manufacturer's instructions. Libraries were sequenced and lung tissue mRNA profiles from $\mathrm{Kras}^{L A 2}$ and $m i R-301 a^{-/-} ; K_{r a s}{ }^{L A 2}$ mice in duplicate were generated with the High-Seq 2000 Illumina sequencing platform by Cofactor Genomics. 


\section{DEG identification and bioinformatics analysis}

The relative transcript abundance was measured in reads per kilobase of exon per million mapped reads (RPKM). DEGs were identified and analyzed by web online service from cofactor genomic company with an unpaired student's t test with $P$ value cutoff of 0.05 and fold change more than 2.0 (upregulation) or less than 0.5 (downregulation). The $P$ value obtained for DEG were adjusted by applying false discovery rate (FDR) method to correct for multiple hypothesis testing. The DAVID gene annotation tool was used to analyze the DEG functions according to the gene ontology terms with significance of $P<0.05$ and false discovery rate $<0.05$. IPA was used to identify enriched molecular pathways, gene networks, upstream regulators, canonical pathways, and cellular biological consequences. We considered both direct and indirect relationships that were experimentally observed predicted in mouse species and we used the "stringent" setting to filter molecules and relationships in tissues and cell lines. For canonical pathways, the $-\log (P$-value $)$ was derived from the right-tailed Fisher's exact. Transcription factors and cytokines were extracted from upstream regulator analysis. This analysis identifies causal molecules associated with differential expression using both the significance and the direction of differential expression to specify causal predictions. The Z-scores and $P$-value based on overlap between predicted and observed regulator-regulated genes (Fishers exact test) were calculated [27]. miR-301a target gene prediction analysis was performed using the miRWalk2.0 database.

\section{Quantitative real-time PCR (qPCR)}

qPCR was performed using the SYBR Green Supermix (Bio-Rad, CA, USA) and CFX96 real-time PCR detection system (Bio-Rad). We analyzed each sample in duplicate with $\beta$-actin as reference (oligonucleotide sequences are provided in Additional file 1: Table S6). Real-time PCR for miR-301a detection was performed using the TaqMan assay (Thermo Fisher, Waltham, MA, USA).

\section{Western blotting analysis}

For western blotting analyses, soluble proteins were subjected to SDS-polyacrylamide gel electrophoresis before being transferred to polyvinylidene difluoride membranes for blotting. Antibodies for Runx3 (D9K6L), $\beta$-catenin (D10A8), integrina4 (D2E1), Pias3 (\#4164), and Pten (D4.3) plus the PathScan multiplex western cocktail (including phosphor-Akt, Phospho-Erk1/2 and Rab11, \#5301) were purchased from Cell Signaling, and antibodies for Adam23 (ab28302), Fam107b (ab175148), Slc25 21 (ab167033), and Nkrf (ab168829) were purchased from Abcam. Antibodies for Fibronectin (A12932), Vimentin (A2666), N-Cadherin (A0433), E-Cadherin (A3044), MMP9 (A0289), MMP2 (A6247) and Ki67(A11005) were purchase from ABclonal
Technology. $\beta$-actin antibody (H11459) was purchased from Sigma. The immunoreactive proteins were visualized with SuperSignal West Dura Chemiluminescent (Thermo Fisher).

\section{Histology immunohistochemistry and immunofluorescence analyses}

Lung tissues were collected at the indicated times and perfused with $10 \%$ neutral-buffered formalin. After $24 \mathrm{~h}$ fixation, tissues were paraffin-embedded and sectioned $(4 \mu \mathrm{m})$. For immunofluorescence staining, deparaffinized and rehydrated sections were treated for antigen retrieval using sodium citrate buffer. For immunohistochemical staining, sections were incubated with primary antibody to CD45 (ab10558, abcam), CD3 (ab16669, abcam), CD4 (ab183685, abcam), CD8 (ab4055, abcam) and F4/80 (ab6640, abcam) overnight at $4{ }^{\circ} \mathrm{C}$. Tissue sections were developed using the Ultra Vision Detection System (Thermo Fisher). For the TUNEL assay, deparaffinized sections were incubated with $20 \mu \mathrm{g} / \mathrm{ml}$ proteinase $\mathrm{K}$ for 15 minat room temperature, washed with PBS, and incubated with TUNEL reaction mixture (Roche Applied Science) for $1 \mathrm{~h}$ at $37^{\circ} \mathrm{C}$ in a humidified atmosphere. For immunofluorescence staining to measure Runx3 and $\beta$-catenin, lung tissue sections were incubated with anti-Runx3 antibody (D9K6L, 1:200, Cell Signaling) and anti- $\beta$-catenin (D10A8, 1:200, Cell Signaling) at $4{ }^{\circ} \mathrm{C}$ overnight. After being rinsed with PBS, the sections were incubated with Alexa Fluor-488 goat anti-rabbit (1:100, Invitrogen) or Alexa Fluor-647 donkey anti-mouse (1100, Invitrogen) for $2 \mathrm{~h}$ at room temperature. After another PBS rinse, the sections were incubated with $1 \mu \mathrm{g} / \mathrm{ml}$ 4',6-diamidino-2-phenylindole for $5 \mathrm{~min}$, and images were acquired using an Olympus IX51 fluorescence microscope and cellSens software (version 1.5).

\section{Elisa}

To determine IFN- $\gamma$ secretion ex vivo, lung tissues were minced, weighed, and incubated with DMEM medium at $37^{\circ} \mathrm{C}$ for $48 \mathrm{~h}$. IFN- $\gamma$ concentration in culture supernatant was measured using the Mouse IFN- $\gamma$ Platinum ELISA kit (Thermo Fisher) according to the manufacturer's protocol.

\section{Flow cytometry}

Lung tissues were minced and filtered to make a single-cell suspension. Cells were stained with anti-CD3-FITC (BD PharMingen, San Diego, CA, USA). After fixation and permeabilization, cells were stained with anti-IFN- $\gamma$-PE and isotypic mAbs (BD PharMingen). For flow cytometry analysis of B16 metastatic tumor models, single-cell suspensions were stained with anti-CD3-APC, anti-CD4-Alexa Fluor 488, anti-CD8-PE, anti-CD11b-APC, and anti-F4/80-Alexa Fluor488. All 
events were acquired using CytoFLEX (Beckman Coulter) equipment according to standard procedures.

\section{RNA interference and miR-301a inhibition}

Using Lipofectamine RNAiMax reagent, NSCLC cell lines were transfected with $25 \mathrm{nM}$ siRNA duplexes targeting PTEN, PIAS3, and RUNX3. After $48 \mathrm{~h}$, the cells were collected, and silencing was measured. siRNA duplex oligonucleotides were purchased from Dharmacon (Dharmacon, Lafayette, CO, USA). For miR-301a inhibition in A549 cells, an LNA-anti-miR-301a inhibitor (Exiqon, Qiagen) was used for transfection, and cells were collected after $48 \mathrm{~h}$. The control was the LNA-miRNA Negative Control A; it has no more than $70 \%$ homology to any sequence in the human genome.

\section{Cell proliferation and migration assay}

Cell proliferation was determined using the Cell Counting Kit-8 (CCK-8) kit (Dojindo Molecular Technologies, Inc., China) according to the manufacturer's protocol. For the cell migration assay, A549 cells were suspended in 1\% FBS DMEM, incubated at $37^{\circ} \mathrm{C}$ for $2 \mathrm{~h}$, and then placed in the upper transwell chambers. The lower chambers were filled with DMEM with 5\% FBS. After $24 \mathrm{~h}$, the inserts were removed, and inner side was wiped with a cotton swab. The cells were fixed with $70 \%$ ethanol, stained with Giemsa, and counted under light microscopy.

\section{In vivo administration of Runx3 shRNA lentivirus}

For in vivo knockdown of Runx3, the shRNA1-Runx3 sequence was: AGGAGCGGTCAAACTGGCGG; shRN A2-Runx3: TTGTGAGCGTGAAACTCTTC; shRNA3-R unx3: ATCGAAGGTCGTTGAACCTG; nonsense sequence to Runx3 (shRNA-control): GGTGTGCAGTTGGAATGTA. Sequences were synthesized and ligated into psiF-copGFP vectors (System Biosciences, Mountain View, CA, USA). $293 \mathrm{~T}$ cells were seeded in a $10-\mathrm{cm}$ plate and transfected with $5 \mu \mathrm{g}$ pRSV-rev, $5 \mu \mathrm{g}$ pMDL-rre, $5 \mu \mathrm{g}$ pMD2.G, and $10 \mu \mathrm{g}$ shRNA plasmid construct. Then the cells were cultured at $37^{\circ} \mathrm{C}$ for $48 \mathrm{~h}$, and the virus was harvested by centrifuging the cells at $2000 \mathrm{~g}$ for $10 \mathrm{~min}$ followed by filtration through a $0.45 \mu \mathrm{m}$ filter. Viruses were tittered by serial dilution and transfected into $293 \mathrm{~T}$ cells with $8 \mu \mathrm{g} / \mathrm{ml}$ polybrene, and positive cells with green fluorescent protein were counted by flow cytometry after $48 \mathrm{~h}$ transfection. Then $1 \mathrm{X}^{8} 0^{8} \mathrm{TU} / \mathrm{ml}$ lentivirus supernatant was injected into mice via the tail vein, and at the indicated times, lung tissue was collected, and western blotting and fluorescence microscopy were performed to ensure silencing was achieved.

\section{Statistical analysis}

All statistical analysis was carried out using SPSS16.0 software (SPSS Inc. Chicago, IL, USA). An unpaired two-tailed Student's $t$-test was performed for two-group comparisons and one-way analysis of variance (ANOVA) analysis was performed for multiple group comparisons.

\section{Results}

Transcriptional signature analysis of lung tissues from

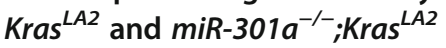

To investigate the role of miR-301a onset lung tumorigenesis, we performed RNA sequencing using total RNA isolated from lung tissues of $\mathrm{Kras}^{L A 2}$ and $\mathrm{miR}^{\mathrm{L}} 301 \mathrm{a}^{-/-} ; \mathrm{K}-$ $\operatorname{ras}^{L A 2}$ mice at age of 9 weeks, when the expression of miR-301a is highest [15]. We identified a total of 1641 DEGs (1166 upregulated and 475 downregulated) in lung tissue between $m i R-301 a^{-/-} ; K_{r a s}{ }^{L A 2}$ mice and $\mathrm{Kra}$ $s^{L A 2}$ mice (Fig. 1a, GSE109238). By analyzing the significant biological processes, we found that immune system process and cell cycle were the most significant gene ontology terms, and B cell activation and T cell differentiation were both significantly annotated (Fig. 1b, Additional file 1: Table S1 and Table S2). Ingenuity Pathway Analysis (IPA) revealed the most enriched canonical pathways involved in B cell development, primary immunodeficiency signaling, cell cycle control of chromosomal replication, iCOS-iCOSL signaling in $\mathrm{T}$ helper cells, CD28 signaling in $\mathrm{T}$ helper cells, and the Th1 pathway (Fig. 1c, Additional file 1: Table S3).

Next, we determined differences in transcription factors and cytokines involved in lung tumorigenesis in miR-301$a^{-/-} ; K_{r a s}^{L A 2}$ mice compared to Kras ${ }^{L A 2}$ mice. As shown in Fig. 1d, transcription activation factors with high Z-scores were $\operatorname{Irf} 3, \operatorname{Tb} x 2, \operatorname{Irf7}$, E2f1, Stat1, Pou2f2, Irf1, Ccnd1 and Irf5, whereas the most significant inhibitory transcription factors were Nupr1, Rb1, Prdm1, Smarcb1, Tfeb, Rbl1, Trim24, E2f6, Kdm5b, Bcl3, Klf3, Hoxa3, Tgfb1l1, Prsa and Eif4g2 (Fig. 1d). The cytokines with significant activation $\mathrm{Z}$ scores are Ifng, Il21, Ifna2, Ifnl1, Ifnb1, Csf2, Ifna1, Il2, Cd40lg and Il27, and those with high inhibition Z-scores included Ccl6, Il13, Il17a, Il10, Ccl2 and Csf3 (Fig. 1e). The most highly implicated IPA network was "DNA Replication, Recombination and Repair, Cell Morphology, and Cancer, Hematological Disease, Immunological Disease." We merged the total 5 networks related to the cell cycle and immune response pathways and found that IFNG (IFN- $\gamma)$ and CTNNB1 ( $\beta$-catenin) were in the core modules within the whole network (Additional file 2: Fig. S1a). Specifically, 283 molecules were identified to be related to lung cancer and the total Z-score of 0.773 for all 283 molecules was predicted to be inhibited (Additional file 1: Table S4). In addition, 47 molecules were identified to be related to $\mathrm{CD}^{+} \mathrm{T}$ lymphocytes, and their predicted activation state was "activated," with a total Z-score of 2.657 (Additional file 1: Table S5). These results support a role of miR-301a in mediating anti-tumor immune response during lung tumorigenesis. 


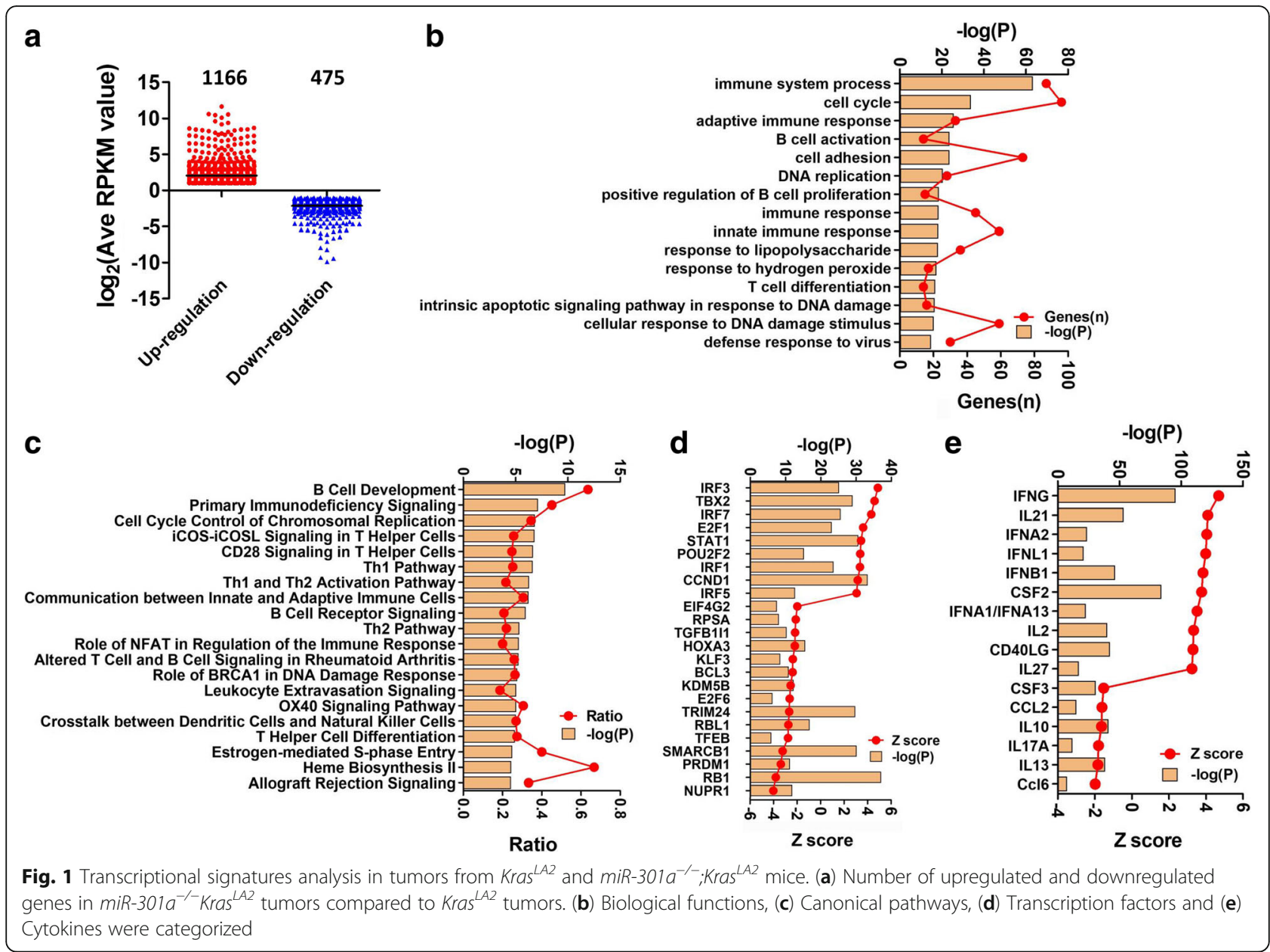

miR-301a deficiency recruits T cells and elevates IFN- $\gamma$ in the tumor microenvironment

To investigate the role of miR-301a in the development of lung cancer, we first compared lung tumor between $\operatorname{Kras}^{L A 2}$ and miR-301a $^{-/-} ; \mathrm{Kras}^{L A 2}$ mice at age of 9 weeks. Consistent with our previous results [15], hematoxylin and eosin (H\&E) staining (Fig. 2a) of $m i R-301 a^{-/-}$;Kra$s^{L A 2}$ lung showed significantly less hyperplasia as well as fewer alveolar adenomas compared with $\mathrm{Kras}^{L A 2}$ mutant mice (Fig. 2a). We next evaluated the alteration of infiltrating immune cells in lung tumors. We found no significant difference in the number of $\mathrm{CD} 45^{+}$cells in lung tumors between $m i R-301 a^{-/-} ; K_{r a s}^{L A 2}$ mice and Kras ${ }^{L A 2}$ mice (Fig. 2b). However, a greater number of $\mathrm{CD}^{+}$, $\mathrm{CD}^{+}$and $\mathrm{CD}^{+} \mathrm{T}$ cells were observed in $\mathrm{miR}-301 \mathrm{a}^{-/-} ; \mathrm{K}-$ ras $^{L A 2}$ mice compared to $\operatorname{Kras}^{L A 2}$ mice. (Fig. 2c-e). The number of infiltrating macrophages, as judged by immunostaining with F4/80 antibody, did not significantly differ between the two groups (Fig. 2f). Furthermore, we evaluated cell proliferation and apoptosis in lung tumors. There were significantly fewer $\mathrm{Ki}^{+} 7^{+}$tumor cells in miR-301a ${ }^{-1-} ; \operatorname{Kras}^{L A 2}$ mice compared with $\operatorname{Kras}^{L A 2}$ mice
(Fig. 2g). However, there was no significant difference in cell apoptosis between $m i R-301 a^{-1-} ; K_{r a s}^{L A 2}$ mice and Kras $^{L A 2}$ control mice (Fig. 2h).

We postulated that miR-301a deletion protects against tumor formation by restraining the pro-inflammatory process. We found significantly lower gene expression of cytokines IL6, IL1 $\alpha$, IL1 $\beta$, IL22 and IL23 in the lung tumors from $m i R-301 a^{-/-} ; K_{r a s}{ }^{L A 2}$ mice than those from $K_{r a s}{ }^{L A 2}$ mice (Fig. 3a). Moreover, IFN- $\gamma$ gene expression validated by qPCR was significantly greater in $m i R-301$ $a^{-/-} ; K_{r a s}{ }^{L A 2}$ lung tissues compared with $\mathrm{Kras}^{L A 2}$ lung tissue (Fig. 3a and b), yet IFN- $\gamma$ level did not differ significantly between WT and $m i R-301 a^{-/-}$lung tissues (Fig. 3b). We noted that from the transcription signature analysis, IFN $-\gamma$ was the most significantly upregulated cytokine in $\mathrm{miR}_{-} 301 \mathrm{a}^{-/-} ; \mathrm{Kras}^{L A 2}$ lung tissues compared with $\mathrm{Kras}^{L A 2}$ lung tissues. As this cytokine is secreted from cells in the lung mucosa-associated lymphoid tissue, we next isolated the whole lung from mice and examined cytokine secretion ex vivo. As shown in Fig. 3c, secretion of IFN- $\gamma$ increased with miR-301a deletion in Kras-mutated mice. IFN- $\gamma$ is produced primarily by $\mathrm{CD}^{+}$ 


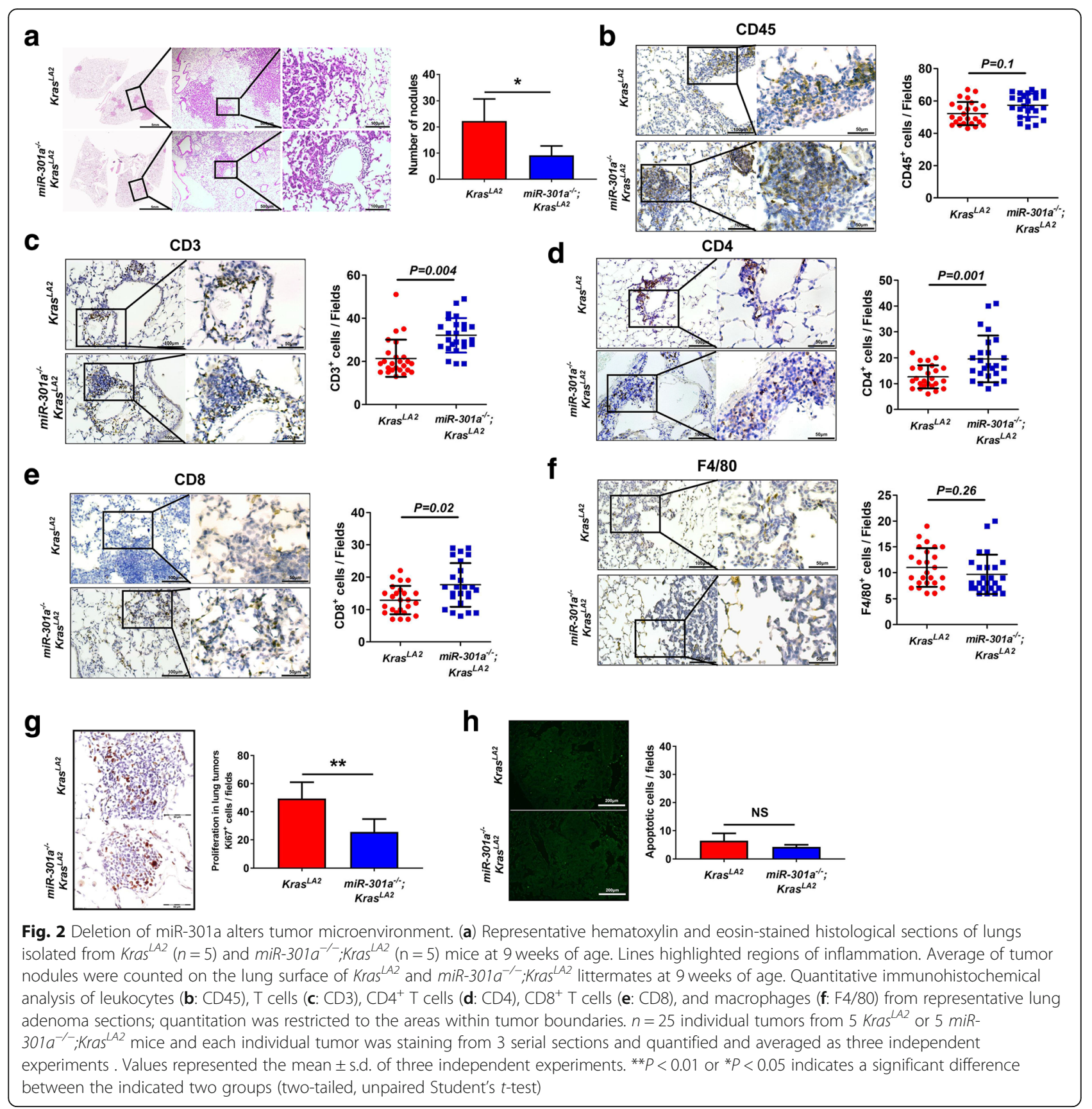

T cells, $\mathrm{CD}^{+} \mathrm{T}$ cells, and NK cells. To further investigate IFN- $\gamma$ expression in T cells, we evaluated $\mathrm{CD}^{+} \mathrm{T}$ cells by flow cytometric analysis. A higher frequency of IFN- $\gamma$ producing $\mathrm{CD}^{+} \mathrm{T}$ cells was detected in whole-lung tissues from $\mathrm{miR}^{-301 a^{-/}} ; \mathrm{Kras}^{L A 2}$ mice than those from $\mathrm{Kras}^{L A 2}$ mice (Fig. 3d and e). In addition, we isolated $\mathrm{CD}^{+}, \mathrm{CD}^{+}$, and $\mathrm{CD}^{+} \mathrm{T}$ cells from WT and $m i R-301 a^{-1-}$ lungs and measured the basal IFN- $\gamma$ level when miR-301a was deleted. We found that IFN- $\gamma$ expression did not differ between $\mathrm{T}$ cells isolated from lung tissues of WT and miR-301 ${ }^{-/-}$mice (Fig. 3f). These results implicate that
miR-301a deficiency recruits $\mathrm{CD}^{+} \mathrm{T}$ cells to the tumor microenvironment, which leads to higher IFN- $\gamma$ expression in early lung tumorigenesis.

\section{miR-301a targets Runx3 in lung tumorigenesis}

We used a comprehensive microRNA-target predicting database, miRWalk, which integrate six bioinformatic tools - Targetscan6.2, miRWalk 2.0, miRDB4.0, miRanda-rel2010, RNA22v2, and PITA -- to predict the potential targets of miR-301a. We identified 1471 potential target genes of miR-301a, which were present in more 

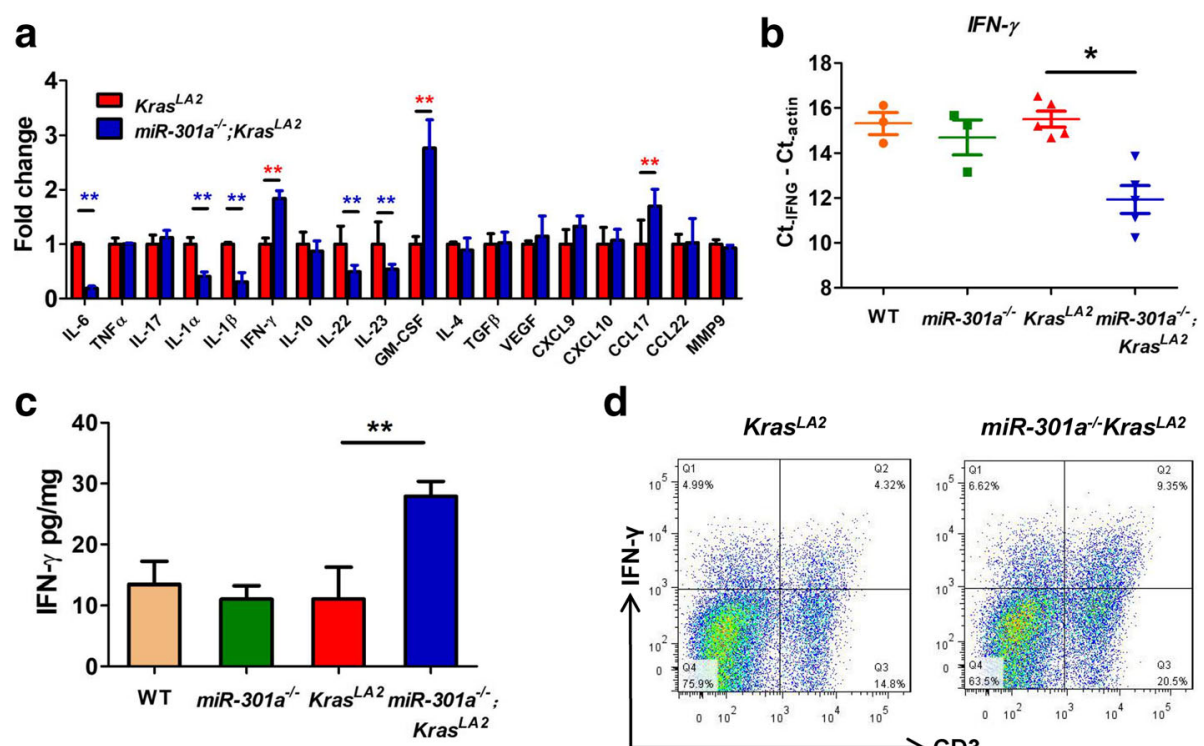

d
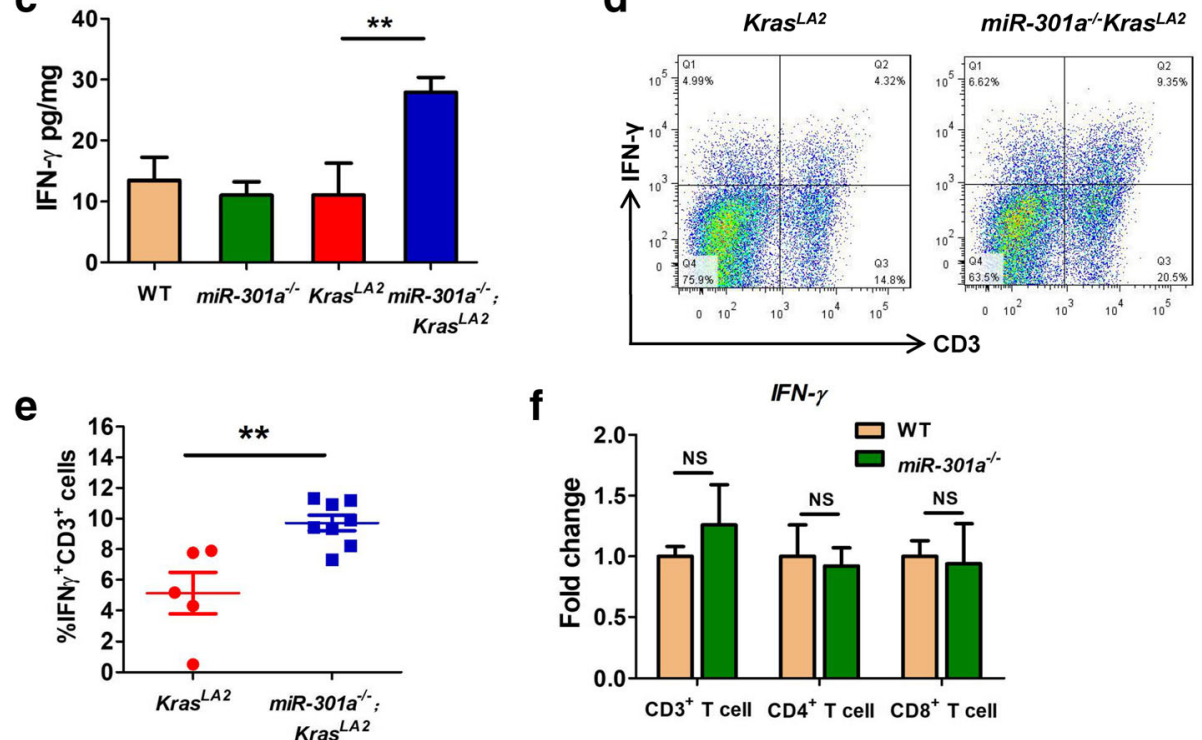

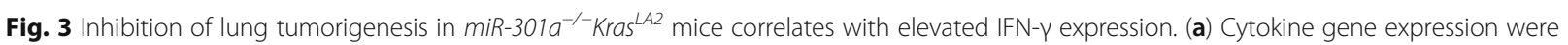
measured by qPCR in lung tumors isolated from $\operatorname{Kras}^{L A 2}(n=5)$ and miR- $^{201 a^{-1-}} \operatorname{Kras}^{L A 2}(n=5)$ mice at 9 weeks of age. (b) Relative expression IFN-

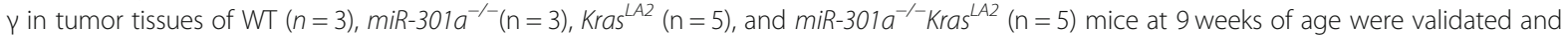
determined by qPCR. (c) Single-cell suspensions were isolated from lung tissues ( $n=5$ per group), and IFN- $\gamma$ secretion ex vivo was determined by ELISA. (d) Representative results of IFN- $\gamma$ expression by $\mathrm{CD}^{+} \mathrm{T}$ cells isolated from lung tumors in 9-week-old $\operatorname{Kras}^{\mathrm{LA2}}(\mathrm{n}=5)$ and $m i R-$

$301 a^{-1-} \mathrm{Kras}^{\mathrm{LA2}}$ mice $(n=8)$. (e) The percentage of IFN- - -positive and CD3-positive cells was counted using flow cytometric analysis of lung tissues

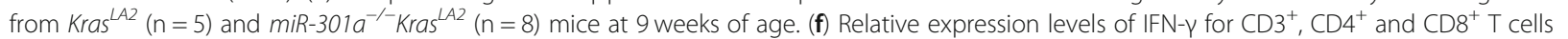
of lung tissues from WT $(n=5)$ and miR-301 $a^{-1-}$ mice $(n=5)$. Values represented the mean \pm s.d. of three independent experiments. ${ }^{* *} P<0.01$ or ${ }^{*} P<0.05$ indicates a significant difference between the indicated groups (two-tailed, unpaired Student's $t$-test in a, e and $f$ and one-way analysis of variance (ANOVA) in $\mathbf{b}$ and $\mathbf{c}$ ). NS, not significant

than 4 bioinformatic tools (Fig. 4a). Next, we compared all up-regulated DEGs identified between $\mathrm{Kras}^{\mathrm{LA2}}$ and miR-301a ${ }^{-1-} ;$ Kras $^{L A 2}$ mice to those 1471 predicted genes. We found that 102 genes overlapped between upregulated DEGs and predicted miR-301a target genes (Fig. 4b). Based on the reads per kilobase of exon per million mapped reads (RPKM) value $\left(P<0.05 ; \log _{2}\right.$ (fold change) $>$ 1 ) and gene function, we chose 6 tumor suppressor genes (Itga4, Slc25a21, Adam23, Runx3, Bach2 and Fam107b)

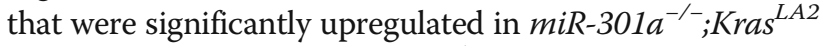
lung tissues compared to $\mathrm{Kras}^{L A 2}$ lung tissues. As shown by quantitative real-time PCR, upregulation of all 6 genes was significantly greater in lung tissues from miR-301$a^{-/}$;Kras ${ }^{L A 2}$ mice than that from $\operatorname{Kras}^{L A 2}$ mice (Fig. 4c).
These results indicate these 6 genes are potential targets of miR-301a in Kras-driven lung tumorigenesis.

IPA interaction network analysis showed that $\beta$-catenin is present in the core modules in the merged network (Additional file 2: Figure S1a) and indicated that Runx3 affected the $\beta$-catenin signaling pathway (Fig. 4d). microRNA-target predicting analysis also revealed a major binding site for miR-301a within the Runx3 RNA 3'UTR (Additional file 2: Figure S2a). Using a luciferase reporter system, we determined miR-301a directly binds the Runx3 mRNA and down-regulates Runx3 expression (Additional file 2: Figure S2b and 2c). Next, we determined whether miR-301a deletion affected Runx3 and $\beta$-catenin expression in lung tumorigenesis by western blotting and 


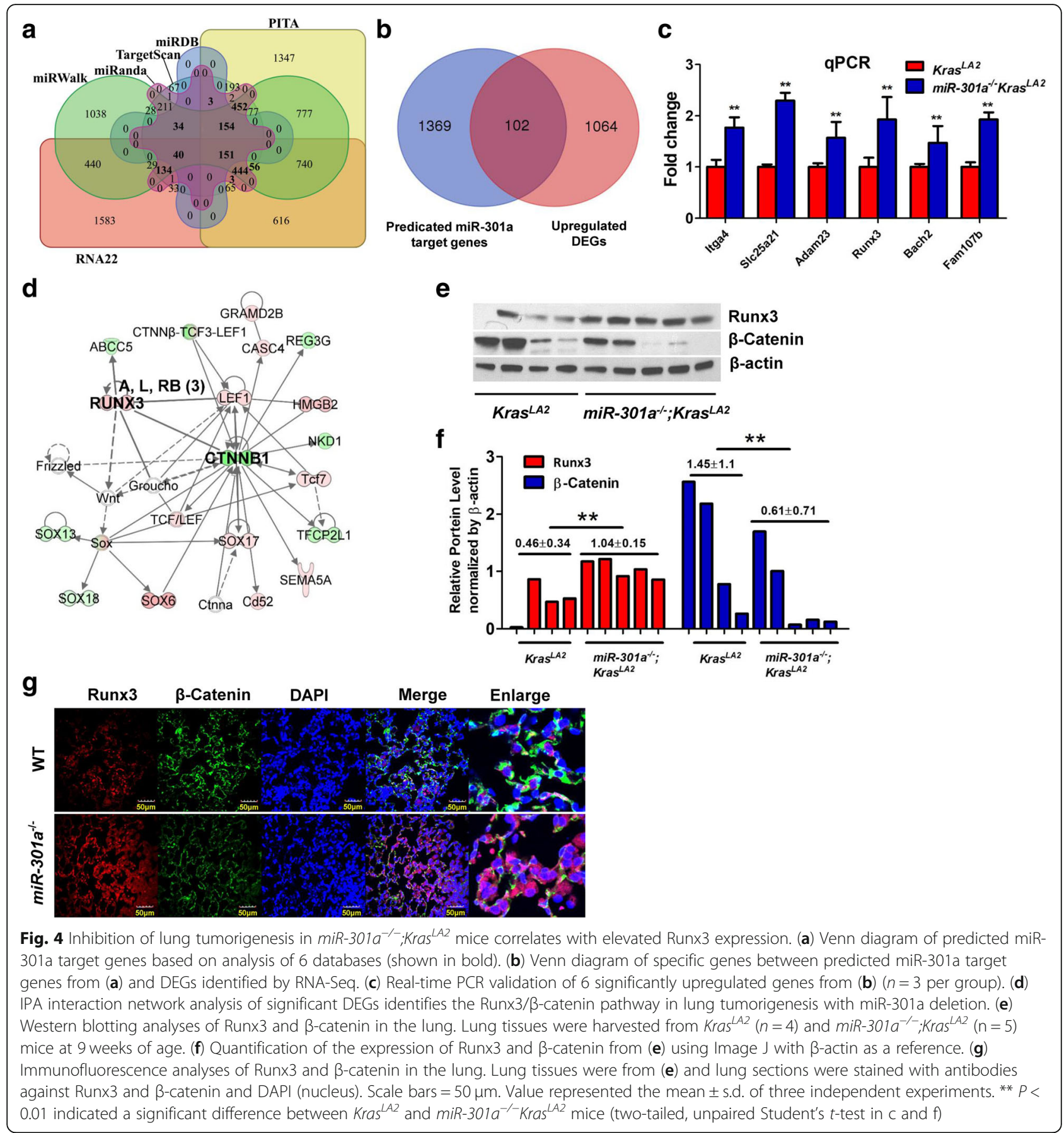

immunofluorescence analyses. As shown in Fig. 4e and f, Runx3 expression was significantly upregulated, whereas $\beta$-catenin expression was down-regulated, in lung tissues from $\mathrm{miR}-301 a^{-/-} ; \mathrm{Kras}^{L A 2}$ mice than that from $\mathrm{Kras}^{L A 2}$ mice. These results were further confirmed by immunofluorescence analysis (Fig. 4g). Taken together, these results indicate that miR-301a directly targets the Runx3 mRNA, and the protective role of miR-301a deficiency in
Kras-driven lung tumorigenesis is associated with upregulation of Runx3 and downregulation of $\beta$-catenin.

Inhibition of miR-301a reduces cellular proliferation and migration in NSCLC cell lines

To determine whether elevating RUNX3 by miR-301a deletion alters lung tumor cell phenotype, we first measured the expression of miR-301a and RUNX3 in 
noncancerous lung epithelial cell line 16HBE and NSCLC cell lines PC9, H1975, A549 and H1299. We found that miR-301a was highly expressed in NSCLC cell lines as compared with $16 \mathrm{HBE}$ cells as determined by quantitative real-time PCR (Fig. 5a). We noted that of the six genes validated by RNA-sequencing, only RUNX3 was significantly downregulated in these four NSCLC cell lines as compared with 16HBE cells (Fig. 5b and Additional file 2: Figure S3a and 3b). Next, we chose two NSCLC cell lines, the Trp53-wt lung cancer A549 line and Trp53-null lung cancer H1299 line, to further evaluate the role of miR-301a and RUNX3 in lung tumor cells. Introducing the miR-301a inhibitor, locked nucleic acid (LNA)-anti-miR-301a, led to upregulation of RUNX3 protein expression in A549 and H1299 cells (Fig. 5c and d). Furthermore, we found that miR-301a inhibition with 5 pmol and 10 pmol of LNA-anti-miR-301a at $48 \mathrm{~h}$ and $72 \mathrm{~h}$ significantly reduced the proliferation of A549 cells (Fig. 5e), but not H1299 cells (Fig. 5f). Yet concomitant knockdown of RUNX3 did not reverse the reduced cellular proliferation mediated by miR-301a inhibition in A549 cells (Fig. 5g and h), indicating that other miR-301a target genes are involved in regulating cellular proliferation.

PTEN is a miR-301a target that suppresses cell and tumor growth in breast cancer [28], bladder cancer [29], and sarcoma [30]. PTEN mRNA level was significantly lower in 4 NSCLC cell lines than in 16HBE cells (Additional file 2: Figure S4a). PTEN protein levels was significantly upregulated by miR-301a inhibition in A549 cells, but not in H1299 cells (Additional file 2: Figure S4b). Knockdown of PTEN via small interfering RNA (siRNA) significantly enhanced proliferation of A549 cells when miR301a was inhibited (Additional file 2: Figure S4c and $4 d)$. We next measured protein expression of Pten and two Ras effectors, phosphor-Akt and phosphor-Erk, in lung tumors from $\mathrm{Kras}^{L A 2}$ and $\mathrm{miR}^{2} 301 a^{-/-} ; \mathrm{Kras}^{L A 2}$ mice. We did not find significant changes in protein levels of Pten, phosphor-Akt and phosphor-Erk (Additional file 2: Figure S4e and 4f). miR-301a activates both NF- $k B$ and Stat3 pro-inflammatory pathways to facilitate lung tumorigenesis [15] by targeting Nkrf and Pias3, respectively [12, 31]. We evaluated the expression of these two miR-301a target genes. However, Pias3 and Nkrf were down-regulated in lung tumors from $m i R-301 a^{-1-} ; \mathrm{Kras}^{\mathrm{LA2}}$ mice compared with those in $\mathrm{Kras}^{\mathrm{LA2}}$ mice (Additional file 2: Figure S4e). Overall, these data demonstrate that miR-301a deficiency did not upregulate the expression of its 3 target genes (Pten, Pias3 and Nkrf) during Kras-driven lung tumorigenesis.

As RUNX3 inhibits tumor cell metastasis through the regulation of the Wnt signaling pathway $[18,21]$, we sought to determine whether inhibition of miR-301a reduces cell migration by targeting RUNX3. We measured the migration of A549 and H1299 cells using a transwell migration assay. Cell migration was significantly reduced when LNA-anti-miR-301a was introduced into A549 and H1299 cells, whereas concomitant RUNX3 knockdown partially reversed the migration phenotype (Fig. $5 \mathrm{i}$ and $\mathrm{j}) . \beta$-catenin expression was downregulated in both A549 and H1299 cells upon miR-301a inhibition (Fig. $5 \mathrm{k}$ ). In addition, we also measured several extracellular matrix (ECM) associate proteins including fibronectin, vimentin, $\mathrm{N}$-cadherin, E-cadherin MMP9 and MMP2 in both A549 and H1299. Our results shown that inhibition of miR-301a in A549 and H1299 significantly reduced $\mathrm{N}$-cadherin and MMP9 expression but increased E-cadherin expression (Fig. 5l). Collectively, these data indicated that miR-301a may have a general impact in mesenchymal fate of lung cancer cells and provide strong evidence to support elevated $R U N X 3$ expression contributes to attenuated cellular migration in lung cancer cells with miR-301a inhibition and reduced lung tumorigenesis in miR-301a deficient mice.

\section{Deletion of miR-301a in mice inhibits tumor cell metastasis by elevating Runx 3 and $T$ cell responses}

To evaluate the function of miR-301a and Runx3 in regulating tumor metastasis, we intravenously injected the melanoma cell line (B16) and Lewis lung carcinoma (LLC1) cells into WT and $m i R-301 a^{-/-}$mice. Lung tumors that developed from either B16 or LLC1 cells in miR-301a ${ }^{-/-}$mice were significantly smaller than those in WT mice by visual inspection (Fig. 6a and b) and by H\&E staining (Fig. 6c). Consistent with the results from Kras mutation mice, cell proliferation, but not apoptosis was significantly inhibited in B16 tumor from miR-301a ${ }^{-/-}$mice compared with that in WT mice (Additional file 2: Figure S5a and 5b). We next examined Runx3 expression in metastatic tumors using immunostaining. Runx3 was barely expressed in B16 tumors from WT mice, however, it was highly expressed in B16 tumors from $m i R-301 a^{-1-}$ mice (Fig. $6 \mathrm{~d}$ and e). To determine whether miR-301a deletion raises Runx3 expression in tumor-infiltrating immune cells, we isolated $\mathrm{CD}^{+} \mathrm{T}$ cells, $\mathrm{CD}_{4}^{+} \mathrm{T}$ cells, CD $11 \mathrm{~b}^{+}$cells (including monocytes and macrophages), and $\mathrm{CD} 11 \mathrm{c}^{+}$cells (including dendritic cells), from B16 tumors developed in WT and $\mathrm{miR}^{-301 a^{-/-}}$mice. We found significantly higher Runx3 expression in tumor-infiltrating immune cells isolated from B16 tumors from $m i R-301 a^{->-}$mice compared to those from WT mice (Fig. $6 \mathrm{f}$ and g). Runx3 is a well-established regulator of $\mathrm{CD}^{+}$and $\mathrm{CD}^{+}{ }^{+} \mathrm{T}$ cells $[32,33]$, so we assessed whether miR-301a deletion alters tumor stromal immune responses. When B16 cells were implanted into WT mice, miR-301a was highly expressed in both tumor-associated $\mathrm{CD}^{+} \mathrm{T}$ cells (Fig. 6h) and $\mathrm{CD} 1 \mathrm{~b}^{+}$cells (Fig. 6i) compared with their counterparts in spleen of un-implanted WT mice. The proportion of tumor-associated $\mathrm{CD}^{+}$and $\mathrm{CD}^{+}{ }^{+} \mathrm{T}$ cells as a 


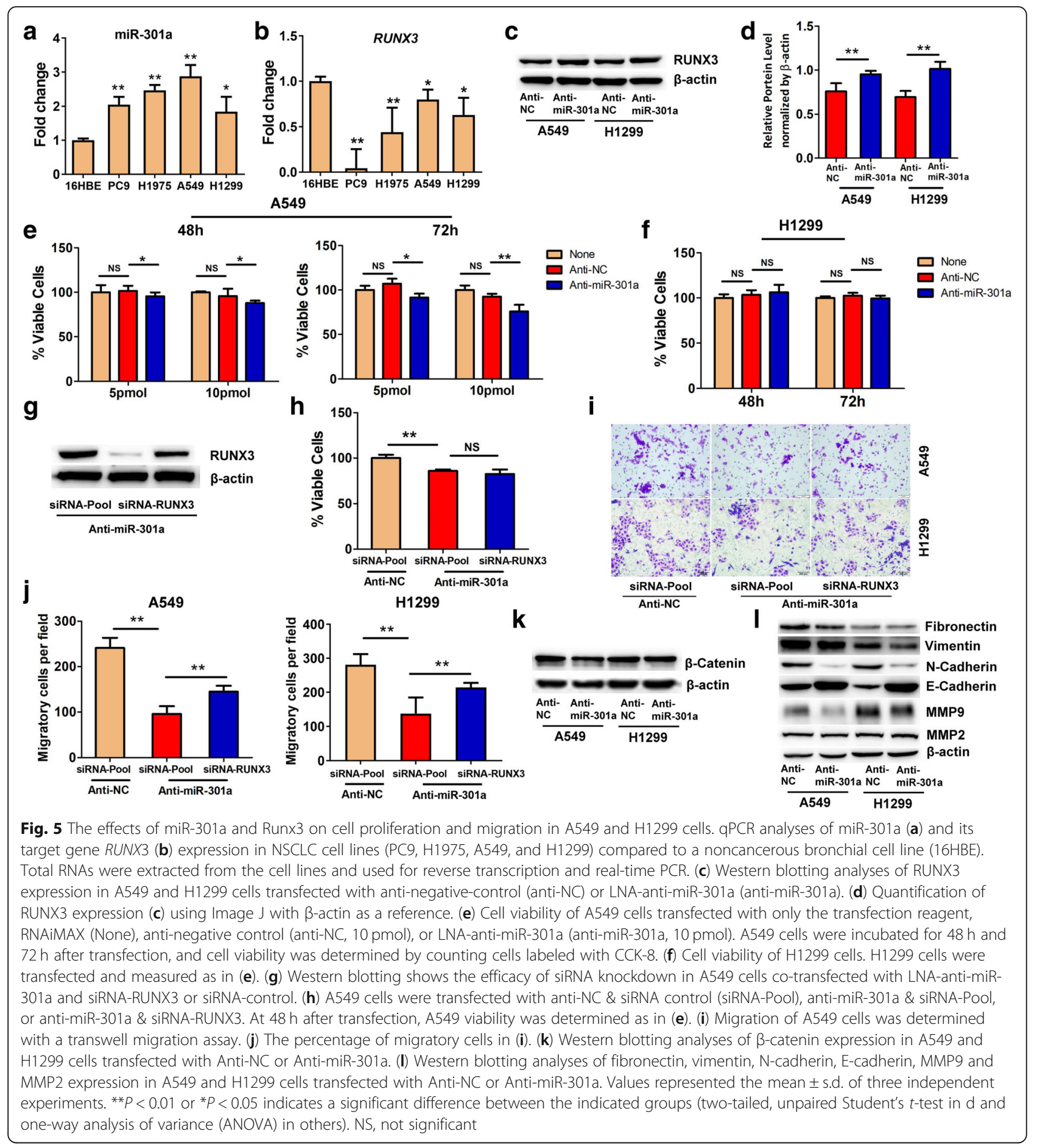

percentage of all immune cells from B16 tumors isolated from $m i R-301 a^{-/-}$mice was higher than those from WT mice (Fig. $6 \mathrm{j}$ and $\mathrm{k}$ ). There was no difference in the proportion of infiltrating macrophages $\left(\mathrm{CD} 11 \mathrm{~b}^{+} \mathrm{F} 4 / 80^{+}\right)$between WT and $m i R-301 a^{-/-}$mice (Fig. 61 and $\mathrm{m}$ ). These data support that attenuated tumor metastasis in $m i R-301 a^{-1-}$ mice is related with elevated Runx3 expression in tumor-associated $\mathrm{T}$ cells. To determine whether increased
Runx3 expression in $m i R-301 a^{-/-}$mice is responsible for recruiting $\mathrm{T}$ cells and reducing B16 tumor cell metastasis, we injected $m i R-301 a^{-1-}$ mice intravenously with shRNA-Runx3 lentivirus after implantation with B16 tumor cells. Compared with the shRNA-control lentivirus, shRNA-Runx3 lentivirus significantly downregulated Runx3 expression in the tumors (Fig. 7a and b). Blockade of Runx3 expression sharply increased tumor metastasis (Fig. 7c and 


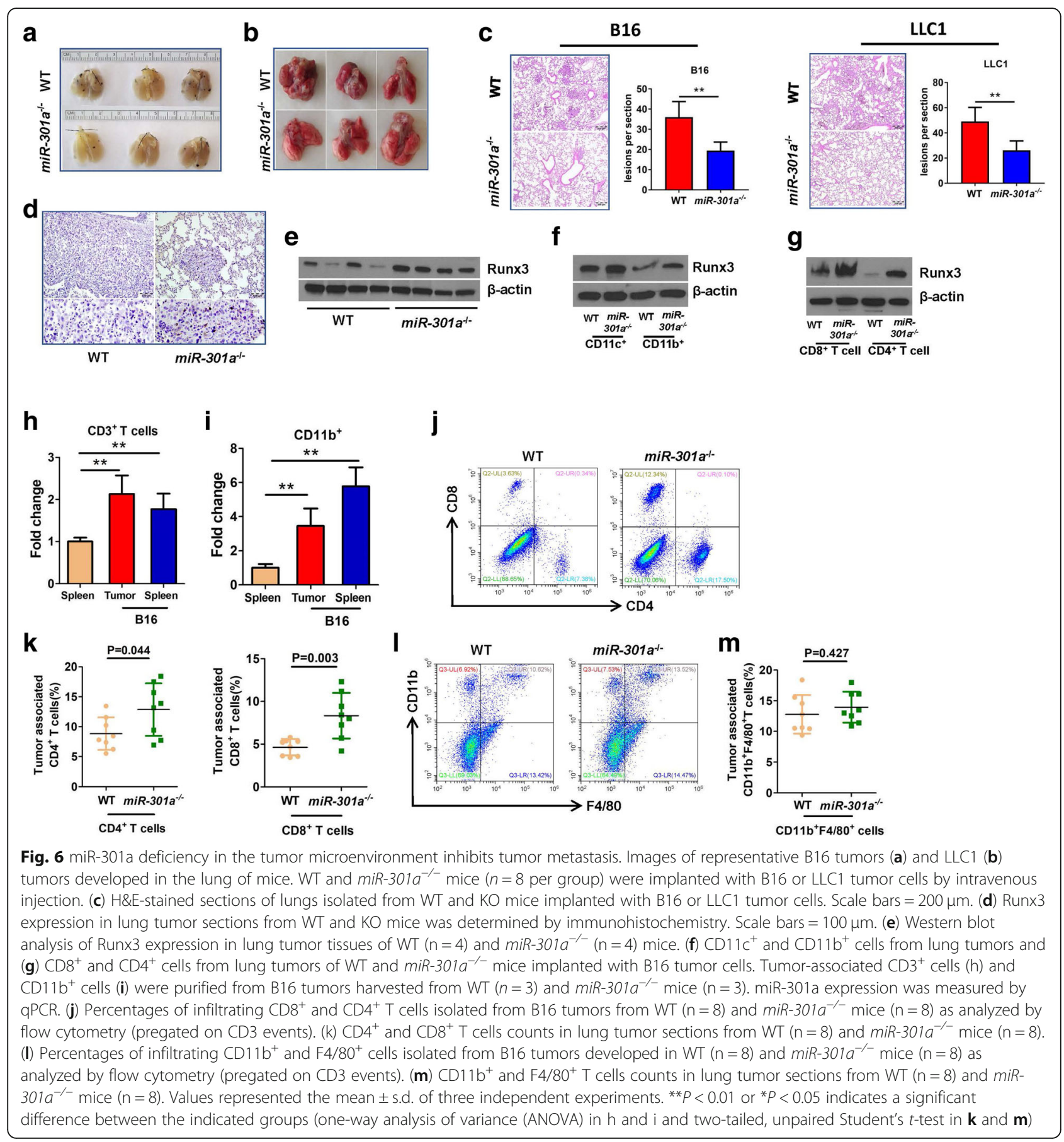

d), accompanied by fewer tumor-infiltrating $\mathrm{CD}^{+}$and $\mathrm{CD}^{+} \mathrm{T}$ cells (Fig. 7e). These data underscored the critical role of miR-301a in immune activation and tumor metastasis through Runx3 suppression during lung tumorigenesis (Fig. 7f).

\section{Discussion}

In this study, we performed RNA-sequencing to identify the potential miR-301a targets and related signaling networks in Kras-induced lung tumorigenesis and determined the role of miR-301a in tumor cell proliferation and migration in NSCLC cell lines and in a syngeneic lung tumor metastasis model. Our major finding is that miR-301a deficiency reactivates the immune response in the tumor microenvironment by recruiting cytotoxic $\mathrm{T}$ cells through negatively regulating Runx3 expression. Moreover, we show that miR-301a controls tumor me-

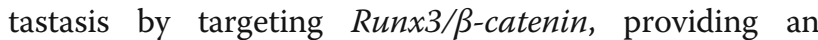


a

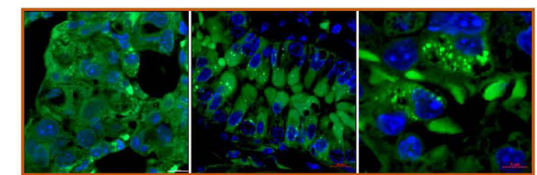

pSIF-copGFP-shRNA-Runx3 b

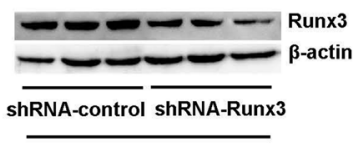

$\operatorname{miR}-301 a^{-/-}$
C

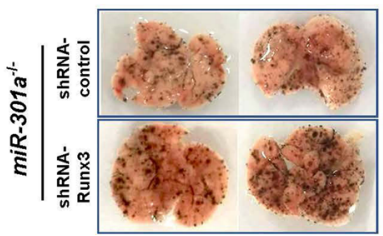

d

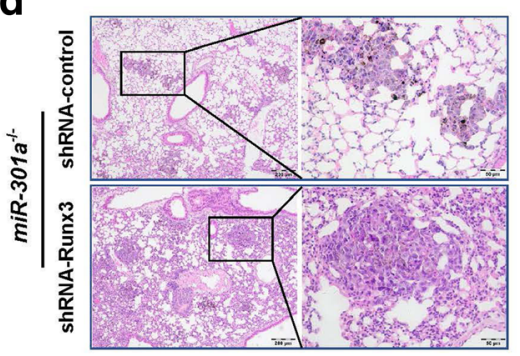

$f$

e

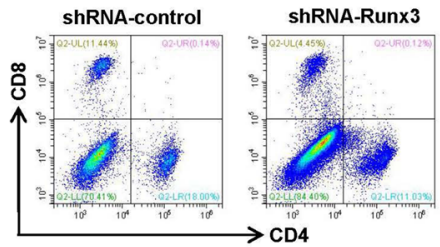

$\mathbf{g}$

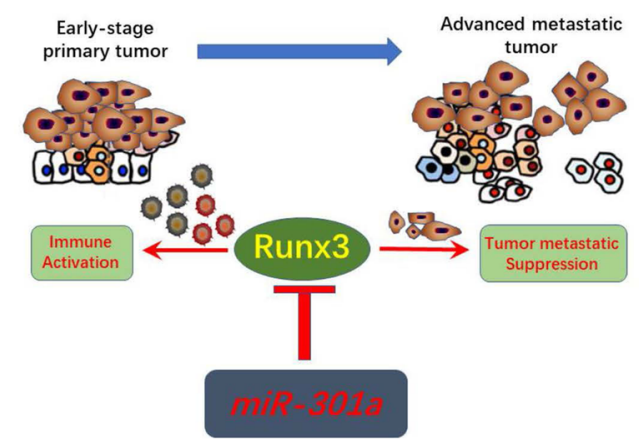

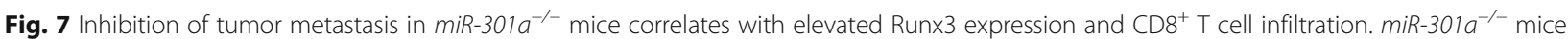
( $n=8$ per group) were implanted with B16 tumor cells by intravenous injection. After $48 \mathrm{~h}$, shRNA control or shRNA-Runx3 lentivirus was injected into miR-301a ${ }^{-1-}$ mice every day until mice were sacrificed and lung tissues collected. (a) Expression of GFP from the shRNA-Runx3 vector in B16 lung tumors. Scale bars $=10 \mu \mathrm{m}$ or $5 \mu \mathrm{m}$. (b) Runx3 expression in lung sections from miR-301 $a^{-1-}$ mice $(n=3)$ with either shRNA-control or shRNA-Runx3 as determined by western blot. (c) Images of representative B16 tumors in the lung from miR-301a ${ }^{-/-}$mice with either shRNAcontrol or shRNA-Runx3 lentivirus ( $n=8$ per group). (d) H\&E-stained sections of lungs isolated from miR-301a ${ }^{-1-}$ mice $(n=8$ per group) with B16 tumor cells. (e) Infiltrating T cells within lung tumors. Right panel: Percentages of infiltrating CD8 ${ }^{+}$and $C D 4^{+} T$ cells isolated from B16 tumors implanted in miR-301 $a^{-1-}$ mice with either shRNA-control or shRNA-Runx3 lentivirus as analyzed by flow cytometry (pregated on CD3 events). Left panel: $\mathrm{CD}^{+}$and $\mathrm{CD} 8^{+}$T cells counts in lung sections ( $\mathrm{n}=8$ per group). ( $\mathbf{f}$ ) Schematic representation of the roles of miR-301a and Runx3 in lung tumorigenesis. Values represented the mean \pm s.d. of three independent experiments. ${ }^{* *} P<0.01$ or $* P<0.05$ indicates a significant difference between the indicated groups (two-tailed, unpaired Student's t-test in f)

underlying mechanism of miR-301a-mediated tumor promotion in NSCLC cells and during lung tumorigenesis.

miR-301a plays a dual role, oncogene-specific effect and pro-inflammatory mediator, in tumorigenesis [15, 34, 35]. Although loss of miR-301a in tumor microenvironment significantly reduces tumor growth, it is unclear which types of tumor-infiltrating immune cells are affected by aberrant expression of miR-301a. Previous studies have shown that miR-301a is markedly up-regulated after $\mathrm{T}$ cell activation [36] and miR-301a inhibition in $\mathrm{CD}_{4}^{+} \mathrm{T}$ cells reduces IL-17 secretion and modulated Th17 development [31], indicating the importance of miR-301a in Th17 cells. Our RNA-Sequencing data identify 49 genes related 
to $\mathrm{CD}^{+} \mathrm{T}$ cell activity within lung tumors developed in Kras-mutated mice with miR-301a knockout. We found, for the first time, that miR-301a controls $\mathrm{CD}^{+}$ tumor-infiltrating lymphocytes in lung tumors. Deletion of miR-301a in tumor immune cells increases the amounts of tumor-infiltrating $\mathrm{CD}^{+} \mathrm{T}$ cells, resulting in attenuated tumor growth and reduced metastasis. Given that activation of Kras in the mouse lung generates an inflammatory process [37], it is likely that the reduced tumor development in miR-301a-deficient mice is due to a limited pro-inflammatory response caused by reactivated immune phenotypic changes. Consistent with that overexpression of miR-301a decreases IFN- $\gamma$ release from antigen-specific cytotoxic $\mathrm{T}$ cells [14], our experiments show that IFN- $\gamma$ release is significantly upregulated in Kras-driven lung tumors upon miR-301a deletion. Such altered IFN- $\gamma$ expression is observed in neither WT nor miR-301a ${ }^{-1-}$ mice without Kras mutation. These data indicate that miR-301a deletion results in enhanced recruitment of $\mathrm{CD}^{+} \mathrm{T}$ cells, which are responsible for increased production of tumoricidal IFN- $\gamma$. In addition to IFN- $\gamma$, several other pro-inflammatory cytokines including IL-6, IL- $1 \alpha$, and IL- $1 \beta$ are down-regulated in $\mathrm{m} i \mathrm{R} 301 \mathrm{a}^{-1-} ; \mathrm{Kra}-$ $s^{L A 2}$ lung tumors, like due to that miR-301a deletion reduces the activation of NF- $\mathrm{kB}$ and Stat3 [12, 31].

Our studies identify RUNX3 as a novel target gene of miR-301a in NSCLC cell lines and Kras mutated mice. RUNX3, as a tumor suppressor gene, is frequently inactivated in human cancer cell lines and patient samples [38, 39]. Loss of RUNX3 occurs more frequently in invasive lung adenocarcinoma than in pre-invasive lesions [40]. Targeted inactivation of Runx3 in mouse lung results in lung adenoma and accelerates Kras-induced development of lung adenocarcinoma as well as loss of Trp53 function, indicating that loss of RUNX3 is a crucial early event in lung tumorigenesis [24]. As a regulator of $\mathrm{T}$ cell development, Runx3 increases the amounts of tumor-infiltrating $\mathrm{CD}^{+} \mathrm{T}$ cells and restrains tumor growth [32]. Our results from Kras transgenic mice and B16/LLC1 syngeneic xenografts show that Runx3 is significantly upregulated in miR-301a-deficient lung tumors. Down-regulation of Runx3 by shRNA in B16 metastatic tumors grown in $m i R-301 a^{-/-}$mice increases the amounts of tumor-infiltrating $\mathrm{CD}^{+} \mathrm{T}$ cells and reduces lung metastasis. Interestingly, down-regulation of PTEN, but not that of RUNX3, reverses the reduced cell proliferation of NSCLC cell lines mediated by miR-301a inhibition.

\section{Conclusions}

Overall, our results show that miR-301a promotes lung tumorigenesis via RUNX3 directly involving tumor cell metastasis and the tumor immune response events. Loss of miR-301a in lung tumor cells inhibits tumor metastasis by targeting RUNX3, whereas deletion of miR-301a in tumor microenvironment reduces the tumorigenesis by elevating $\mathrm{CD}^{+}$cytotoxic $\mathrm{T}$ cells by negatively regulating $R U N X 3$ (Fig. $7 \mathrm{~g}$ ). This is the first demonstration that miR-301a deficiency enhances $\mathrm{CD}^{+}$ $\mathrm{T}$ cell accumulation by negatively regulating Runx 3 that are implicated in the anti-tumor immunity.

\section{Additional files}

\begin{abstract}
Additional file 1: Table S1. Functional annotation clustering for GO (gene ontology) terms involving DEGs in lung tissue between $\mathrm{Kras}^{\text {LA2 }}$

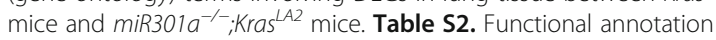
clustering for $\mathrm{GO}$ terms involving up and down regulated genes in lung tissue between $\mathrm{Kras}^{\mathrm{LA2}}$ mice and miR301a ${ }^{-1-} ; \mathrm{Kras}^{\mathrm{LA2}}$ mice. Table S3. The

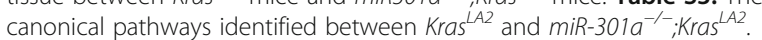
Table S4. 283 molecules related with lung tumors were identified

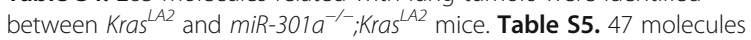
related with $\mathrm{CD}^{+} \mathrm{T}$ lymphocyte were identified between $\mathrm{Kras}^{\mathrm{LA2}}$ and miR-301 $a^{-1-} ;$ Kras $^{\text {LA2 }}$ mice. Table S6. The primer used for real-time PCR assay. (DOCX 103 kb)

Additional file 2: Figure S1. IPA Interaction networks analysis of significant DEGs in lung tissue between $\mathrm{Kras}^{\mathrm{LA2}}$ and $\mathrm{miR}-301 \mathrm{a}^{-1-} \mathrm{Kras}^{\mathrm{LA2}}$ mice and identified IFNG and CTNNB1 as the central node in the top regulated network. Figure S2. Runx3 is a direct target of miR-301a. Figure S3. The mRNA and protein expression of 5 genes in NSCLC cell lines. Figure S4. The effects of PTEN on cell proliferation in A549 and lung tumorigenesis. Figure S5. The effects of miR-301a on cell proliferation and apoptosis in mouse xenografts (DOCX 4049 kb)
\end{abstract}

\begin{abstract}
Abbreviations
EMT: epithelial-to-mesenchymal transition; FDR: false discovery rate; H\&E: hematoxylin and eosin; IPA: Ingenuity Pathway Analysis; LNA: locked nucleic acid; MEFs: mouse embryonic fibroblast; RPKM: reads per kilobase of exon per million mapped reads; RUNX3: transcription factor 3; TGF-

$\beta$ : transforming growth factor- $\beta$; WT: wild-type
\end{abstract}

\section{Acknowledgements}

We wish to thank Dr. Cassandra Talerico for her critical reading of the manuscript.

\section{Availability of data and materials}

The data that support the findings of this study were submitted to the Gene Expression Omnibus Database (Accession: GSE109238). And the data are available from https://www.ncbi.nlm.nih.gov/geo/query/acc.cgi?acc=GSE109238.

\section{Funding}

This study was supported by multiple grants to Xiaodong Ma from the Natural Science Foundation of Guangdong Province of China (No 2017A030311004), the National Natural Science Foundation of China (Nos. 81572399 and 81773249), and the Science and Technology Program of Guangzhou City of China (No. 201707010139). It was also supported by a grant to Fengxue Zhang from the Science Research Project of Guangdong Education Department (No. 2016KZDXM032).

\section{Authors' contributions}

Xun Li, Mingtian Zhong and Jiexuan Wang performed most experiments. Lei Wang and Zhanwen Lin participated in data analysis work and animal experiments. Zi Cao Zhujuan Huang and Fengxue Zhang participated the immunostaining, western blots and assisted in data interpretation. Yong Li, Ming Liu and Xiaodong Ma designed and wrote the manuscript. All authors reviewed the manuscript and approved the submission.

Ethics approval and consent to participate

All mice were kept under pathogen-free conditions, and all mouse experiments were performed under protocols approved by the Institutional Animal Care and Use Committee of South China Normal University and in accordance with the Guide for the Care and Use of Laboratory Animals. 


\section{Consent for publication}

Not applicable.

\section{Competing interests}

The authors declare that they have no competing interests.

\section{Publisher's Note}

Springer Nature remains neutral with regard to jurisdictional claims in published maps and institutional affiliations.

\section{Author details}

${ }^{1}$ Institute for Brain Research and Rehabilitation, Guangdong Key Laboratory of Mental Health and Cognitive Science, Center for Studies of Psychological Application, South China Normal University, Guangzhou 510631, China. ${ }^{2} T$ The Research Center of Basic Integrative Medicine, Guangzhou University of Chinese Medicine, Guangzhou 510006, China. ${ }^{3}$ State Key Laboratory of Respiratory Disease, Guangzhou Institute of Respiratory Health, The First Affiliated Hospital of Guangzhou Medical University, Guangzhou Medical University, Guangzhou 510120, China. ${ }^{4}$ Department of Cancer Biology, Lerner Research Institute, Cleveland Clinic, Cleveland, OH, USA.

\section{Received: 15 December 2018 Accepted: 2 May 2019}

\section{Published online: 23 May 2019}

\section{References}

1. Wistuba II, Gazdar AF. Lung cancer preneoplasia. Annu Rev Pathol. 2006;1: 331-48.

2. DuPage M, Dooley $A L$, Jacks T. Conditional mouse lung cancer models using adenoviral or lentiviral delivery of Cre recombinase. Nat Protoc. 2009; 4:1064-72.

3. Licciulli S, Avila JL, Hanlon L, Troutman S, Cesaroni M, Kota S, Keith B, Simon MC, Pure E, Radtke F, et al. Notch1 is required for Kras-induced lung adenocarcinoma and controls tumor cell survival via p53. Cancer Res. 2013; 73:5974-84.

4. Ma X, Choudhury SN, Hua X, Dai Z, Li Y. Interaction of the oncogenic miR21 microRNA and the p53 tumor suppressor pathway. Carcinogenesis. 2013; 34:1216-23.

5. Gu L, Deng ZJ, Roy S, Hammond PT. A combination RNAi-chemotherapy layer-by-layer nanoparticle for systemic targeting of KRAS/P53 with cisplatin to treat non-small cell lung Cancer. Clin Cancer Res. 2017;23:7312-23.

6. Feldser DM, Kostova KK, Winslow MM, Taylor SE, Cashman C, Whittaker CA, Sanchez-Rivera FJ, Resnick R, Bronson R, Hemann MT, Jacks T. Stage-specific sensitivity to p53 restoration during lung cancer progression. Nature. 2010; 468:572-5.

7. Junttila MR, Karnezis AN, Garcia D, Madriles F, Kortlever RM, Rostker F, Brown Swigart L, Pham DM, Seo Y, Evan Gl, Martins CP. Selective activation of p53-mediated tumour suppression in high-grade tumours. Nature. 2010; 468:567-71.

8. Du L, Schageman JJ, Irnov GL, Hammond SM, Minna JD, Gazdar AF, Pertsemlidis A. MicroRNA expression distinguishes SCLC from NSCLC lung tumor cells and suggests a possible pathological relationship between SCLCS and NSCLCs. J Exp Clin Cancer Res. 2010:29:75.

9. Miko E, Czimmerer Z, Csanky E, Boros G, Buslig J, Dezso B, Scholtz B. Differentially expressed microRNAs in small cell lung cancer. Exp Lung Res. 2009:35:646-64.

10. Mascaux C, Laes JF, Anthoine G, Haller A, Ninane V, Burny A, Sculier JP. Evolution of microRNA expression during human bronchial squamous carcinogenesis. Eur Respir J. 2009:33:352-9.

11. Wang M, Li C, Yu B, Su L, Li J, Ju J, Yu Y, Gu O, Zhu Z, Liu B. Overexpressed miR-301a promotes cell proliferation and invasion by targeting RUNX3 in gastric cancer. J Gastroenterol. 2013;48:1023-33.

12. Lu Z, Li Y, Takwi A, Li B, Zhang J, Conklin DJ, Young KH. Martin R: miR-301a as an NF-kappaB activator in pancreatic cancer cells. EMBO J. 2011;30:57-67.

13. Cao G, Huang B, Liu Z, Zhang J, Xu H, Xia W, Li J, Li S, Chen L, Ding H, et al. Intronic miR-301 feedback regulates its host gene, ska2, in A549 cells by targeting MEOX2 to affect ERK/CREB pathways. Biochem Biophys Res Commun. 2010;396:978-82

14. Pyfferoen L, Mestdagh P, Vergote K, De Cabooter N, Vandesompele J, Lambrecht BN, Vermaelen KY. Lung tumours reprogram pulmonary dendritic cell immunogenicity at the microRNA level. Int J Cancer. 2014;135: 2868-77.
15. Ma X, Yan F, Deng Q, Li F, Lu Z, Liu M, Wang L, Conklin DJ, McCracken J, Srivastava $\mathrm{S}$, et al. Modulation of tumorigenesis by the pro-inflammatory microRNA miR-301a in mouse models of lung cancer and colorectal cancer. Cell Discov. 2015;1:15005.

16. Shi YK, Zang QL, Li GX, Huang Y, Wang SZ. Increased expression of microRNA-301a in nonsmall-cell lung cancer and its clinical significance. J Cancer Res Ther. 2016;12:693-8.

17. Zhang L, Zhang Y, Zhu H, Sun X, Wang X, Wu P, Xu X. Overexpression of miR-301a-3p promotes colorectal cancer cell proliferation and metastasis by targeting deleted in liver cancer-1 and runt-related transcription factor 3. J Cell Biochem. 2019;120:6078-89.

18. Chen F, Liu X, Bai J, Pei D, Zheng J. The emerging role of RUNX3 in cancer metastasis (review). Oncol Rep. 2016:35:1227-36.

19. Sun J, Li B, Jia Z, Zhang A, Wang G, Chen Z, Shang Z, Zhang C, Cui J, Yang W. RUNX3 inhibits glioma survival and invasion via suppression of the betacatenin/TCF-4 signaling pathway. J Neuro-Oncol. 2018;140:15-26.

20. Ito K, Lim AC, Salto-Tellez M, Motoda L, Osato M, Chuang LS, Lee CW, Voon DC, Koo JK, Wang H, et al. RUNX3 attenuates beta-catenin/T cell factors in intestinal tumorigenesis. Cancer Cell. 2008;14:226-37.

21. Voon DC, Wang H, Koo JK, Nguyen TA, Hor YT, Chu YS, Ito K, Fukamachi H, Chan SL, Thiery JP, Ito Y. Runx3 protects gastric epithelial cells against epithelial-mesenchymal transition-induced cellular plasticity and tumorigenicity. Stem Cells. 2012;30:2088-99.

22. Tanaka S, Shiraha H, Nakanishi Y, Nishina S, Matsubara M, Horiguchi S, Takaoka N, Iwamuro M, Kataoka J, Kuwaki K, et al. Runt-related transcription factor 3 reverses epithelial-mesenchymal transition in hepatocellular carcinoma. Int J Cancer. 2012;131:2537-46.

23. Lee JM, Shin JO, Cho KW, Hosoya A, Cho SW, Lee YS, Ryoo HM, Bae SC, Jung HS. Runx3 is a crucial regulator of alveolar differentiation and lung tumorigenesis in mice. Differentiation. 2011:81:261-8.

24. Lee YS, Lee JW, Jang JW, Chi XZ, Kim JH, Li YH, Kim MK, Kim DM, Choi BS, Kim EG, et al. Runx3 inactivation is a crucial early event in the development of lung adenocarcinoma. Cancer Cell. 2013;24:603-16.

25. Overwijk WW, Restifo NP. B16 as a mouse model for human melanoma. Curr Protoc Immunol. 2001; Chapter 20:Unit 2021.

26. Elkin M, Vlodavsky I. Tail vein assay of cancer metastasis. Curr Protoc Cell Biol. 2001, Chapter 19:Unit 1912.

27. Yazdani N, Parker CC, Shen Y, Reed ER, Guido MA, Kole LA, Kirkpatrick SL, Lim JE, Sokoloff G, Cheng R, et al. Hnrnph1 is a quantitative trait gene for methamphetamine sensitivity. PLoS Genet. 2015;11:e1005713.

28. Ma F, Zhang J, Zhong L, Wang L, Liu Y, Wang Y, Peng L, Guo B. Upregulated microRNA-301a in breast cancer promotes tumor metastasis by targeting PTEN and activating Wnt/beta-catenin signaling. Gene. 2014;535:191-7.

29. Egawa H, Jingushi K, Hirono T, Ueda Y, Kitae K, Nakata W, Fujita K, Uemura M, Nonomura N, Tsujikawa K. The miR-130 family promotes cell migration and invasion in bladder cancer through FAK and Akt phosphorylation by regulating PTEN. Sci Rep. 2016;6:20574.

30. Kawano M, Tanaka K, Itonaga I, Iwasaki T, Tsumura H. MicroRNA-301a promotes cell proliferation via PTEN targeting in Ewing's sarcoma cells. Int J Oncol. 2016:48:1531-40.

31. Mycko MP, Cichalewska M, Machlanska A, Cwiklinska H, Mariasiewicz M, Selmaj KW. MicroRNA-301a regulation of a T-helper 17 immune response controls autoimmune demyelination. Proc Natl Acad Sci U S A. 2012;109: E1248-57.

32. Milner JJ, Toma C, Yu B, Zhang K, Omilusik K, Phan AT, Wang D, Getzler AJ Nguyen T, Crotty S, et al. Runx3 programs CD8(+) T cell residency in nonlymphoid tissues and tumours. Nature. 2017;552:253-7.

33. Taniuchi I, Osato M, Egawa T, Sunshine MJ, Bae SC, Komori T, Ito Y, Littman DR. Differential requirements for Runx proteins in CD4 repression and epigenetic silencing during T lymphocyte development. Cell. 2002;111:621-33.

34. Liu L, Nie J, Chen L, Dong G, Du X, Wu X, Tang Y, Han W. The oncogenic role of microRNA-130a/301a/454 in human colorectal cancer via targeting Smad4 expression. PLoS One. 2013:8:e55532.

35. Yue X, Cao D, Lan F, Pan Q, Xia T, Yu H. MiR-301a is activated by the Wnt/ beta-catenin pathway and promotes glioma cell invasion by suppressing SEPT7. Neuro-Oncology. 2016;18:1288-96.

36. Zhang N, Bevan MJ. Dicer controls CD8+ T-cell activation, migration, and survival. Proc Natl Acad Sci U S A. 2010;107:21629-34.

37. Kitajima S, Thummalapalli R, Barbie DA. Inflammation as a driver and vulnerability of KRAS mediated oncogenesis. Semin Cell Dev Biol. 2016;58: 127-35. 
38. Chen X, Deng Y, Shi Y, Zhu W, Cai Y, Xu C, Zhu K, Zheng X, Chen G, Xie Q, Weng $G$. Loss of expression rather than cytoplasmic mislocalization of RUNX3 predicts worse outcome in non-small cell lung cancer. Oncol Lett. 2018;15:5043-55.

39. Lee YS, Bae SC. How do K-RAS-activated cells evade cellular defense mechanisms? Oncogene. 2016;35:827-32.

40. Kim HJ, Park J, Lee SK, Kim KR, Park KK, Chung WY. Loss of RUNX3 expression promotes cancer-associated bone destruction by regulating CCL5, CCL19 and CXCL11 in non-small cell lung cancer. J Pathol. 2015;237: $520-31$

Ready to submit your research? Choose BMC and benefit from:

- fast, convenient online submission

- thorough peer review by experienced researchers in your field

- rapid publication on acceptance

- support for research data, including large and complex data types

- gold Open Access which fosters wider collaboration and increased citations

- maximum visibility for your research: over $100 \mathrm{M}$ website views per year

At $\mathrm{BMC}$, research is always in progress.

Learn more biomedcentral.com/submissions 